\title{
Serodiagnosis of Hepatitis B Virus Infection among Jessu Community of Gombe State, Nigeria
}

\author{
Sheyin Zakka ${ }^{1,2, ~ *, ~ F r a m a ~ I s h a k u ~}{ }^{1}$, Essien Unyime Cosmas ${ }^{1}$, Shindang John ${ }^{1}$, \\ Bigwan Emmanuel Isa ${ }^{1}$
}

${ }^{1}$ Department of Medical Laboratory Science, University of Jos, Jos, Nigeria

${ }^{2}$ School of Medicine and Allied Health Sciences, University of the Gambia, Banjul, Gambia

\section{Email address:}

sheyinzakka@gmail.com (S. Zakka)

\section{To cite this article:}

Sheyin Zakka, Frama Ishaku, Essien Unyime Cosmas, Shindang John, Bigwan Emmanuel Isa. Serodiagnosis of Hepatitis B Virus Infection among Jessu Community of Gombe State, Nigeria. International Journal of Infectious Diseases and Therapy.

Vol. 3, No. 2, 2018, pp. 40-44. doi: 10.11648/j.ijidt.20180302.14

Received: August 8, 2018; Accepted: August 24, 2018; Published: September 17, 2018

\begin{abstract}
Hepatitis B virus causes disease of the liver and is a global health problem that leads to liver cirrhosis and hepatocellular carcinoma. Despite the dangers posed by this silent and deadly disease, there is little or no documented work on Hepatitis B infections in Jessu community, Gombe State, North East Nigeria. This study was undertaken to determine the seroprevalence of Hepatitis B Virus infection and possible risk factors associated with the transmission of HBV. Blood samples $(3 \mathrm{ml})$ were collected from 196 eligible consented subjects and the serum samples were tested for the presence of HBsAg using On Site HBsAg Rapid Test Kit manufactured by CTK Biotech, USA. The OnSite HBV 5-Parameter Rapid Test also manufactured by CTK Biotech, USA was used to confirm those that were positive. Of the 196 eligible subjects examined, 5.6\% were confirmed positive for $\mathrm{HBsAg}, 8.6 \%$ were males and 2.9\% were females. Age distribution of $\mathrm{HBsAg}$ among the population shows the highest seroprevalence of $8.9 \%$ HBsAg in ages $16-30$ years, followed by $4.5 \%$ in ages $31-45$ years while ages $0-15$ years had 3.5\% seroprevalence. Participants who share sharp objects recorded the highest prevalence of $6.3 \% \mathrm{HCV}$ infection followed by blood transfusion with 5.9\% prevalence and those with multiple sex partners had the least prevalence of $1.8 \% \mathrm{HCV}$ infection. The seroprevalence of $5.6 \% \mathrm{HBV}$ in this study indicated the presence of HBV in Jessu Community in Gombe State, North East Nigeria.
\end{abstract}

Keywords: Hepatitis, HBV, Hepatocytes, Hepatocellular Carcinoma, HBsAg, OnSite HBV 5-Parameter Rapid Test

\section{Introduction}

Hepatitis B virus infection is a contagious disease of the liver and a serious public health problem resulting to acute, chronic hepatitis, liver cirrhosis, and hepatocellular carcinoma [1-2]. It is 50 to 100 times more infectious than Human Immunodeficiency Virus (HIV) and 10 times more infectious than hepatitis $\mathrm{C}$ virus [3-7].

Hepatitis B viral infection is caused by hepatitis B virus (HBV) and spread primarily by blood, blood products and other body fluids [8]. The virus infects the liver, interfering with the functions of the liver by replicating in the liver tissues and attaches themselves to the hepatocytes using Pre $\mathrm{S}$ domain of the viral surface antigen, penetrating the cytoplasm and move into the nucleus of the hepatocytes.
During the course of the infection, the host immune response results in viral clearance and hepatocytes damage leading to hepatocellular necrosis and inflammation [9]. HBV itself does not cause cell death; most of the hepatocellular damages associated with HBV infection are mediated by cytotoxic $\mathrm{CD}_{8+}$ T-lymphocytes directed against the viral infected cells. Infection with HBV may lead to acute hepatitis, chronic hepatitis, hepatic failure, liver cirrhosis and Hepatocellular Carcinoma [10].

Sexual transmission of hepatitis B may occur, particularly in unvaccinated men who have sex with men and heterosexual persons with multiple sex partners or contact with sex workers. Infection in adulthood leads to chronic hepatitis in less than $5 \%$ of cases $[8,11]$.

Globally, Hepatitis B virus infection remains one of the most serious health problem facing humans today, with an 
estimated incidence of 4.5 million and mortality of 786,000 deaths per year worldwide with Sub-Saharan Africa, including Nigeria having the highest incidence [12- 13]. Despite the dangers posed by this silent and deadly disease, there is little or no documented work on Hepatitis B infections in Jessu, Gombe State, Nigeria.

\section{Materials and Methods}

\subsection{The Study Area}

The study was carried out in Jessu village of Balanga Local Government Area of Gombe State, North-East, Nigeria. The study covers the period between Augusts December 2017.

\subsection{Ethical Consideration}

Ethical clearance was obtained from the Ethical Committee of Gombe State Specialist Hospital, Gombe, before the commencement of the work.

\subsection{Consent}

The informed consent of each participant was obtained prior to sample collection and analysis.

\subsection{Inclusion Criteria}

All eligible subjects, male and female residence in Jessu Community who gave informed consent were included in the study.

\subsection{Exclusion Criteria}

Subjects who had been vaccinated with the required three doses of the vaccine, those who declined to offer consent and those who are not residence in Jessu Community were excluded from the study.

\subsection{Sample Size}

A sample size of one hundred and ninety- six (196) was calculated according to the formula described by Thrusfield [14].

\subsection{Materials}

OnSite HBsAg Rapid Test manufactured by CTK Biotech, Inc, 6748 Nancy Ridge Drive, San Diego, CA 92121, USA.

OnSite HBV 5-Parameter Rapid Test, manufactured by CTK Biotech, Inc, 6748 Nancy Ridge Drive, San Diego, CA 92121, USA.

\subsection{HBsAg Rapid Test}

\subsubsection{Assay Procedure}

The HBsAg Rapid Test Strips (CTK Biotech, Inc. 6748 Nancy Ridge Drive, San Diego, CA 92121, USA) were brought to room temperature prior to the assay. Three milliliters $(3 \mathrm{ml})$ of plasma were collected into the sample containers. When ready to test, the pouches were opened at the notch and test strips removed. The strips were dipped into the specimen for at least 10 seconds, and the specimens were not allowed to reach above the level indicated by the arrows on the strips. The strips were removed from the specimens and placed on a flat, dry surface.

\subsubsection{Results}

The test results were read within 15 minutes. Negative Control: Only the $\mathrm{C}$ band shows color development. The $\mathrm{T}$ band shows no color development. Positive Control: Both $\mathrm{C}$ and $\mathrm{T}$ bands show color development. The appearance of any burgundy color in the $\mathrm{T}$ band, regardless of intensity, was considered reactive.

\subsection{Hbv Profile}

The OnSite HBV 5-Parameter Rapid Test (CTK Biotech, Inc, 6748 Nancy Ridge Drive, San Diego, CA 92121, USA) is a lateral flow chromatographic immunoassay consisting of 5 test panel strips assembled in one cassette. Each strip of the panel member is composed of a sample pad, colloid gold conjugate pad, nitrocellulose membrane (NC membrane) strip pre-coated with control band ( $\mathrm{C}$ band) and test band ( $\mathrm{T}$ band), and absorbent pad.

\subsubsection{Assay Procedure}

The test components were brought to room temperature prior to assay. The pouch devices were open and placed on a clean, flat surface. The devices were labeled with specimen's ID number. Three Drops of the specimen were dispensed into each of the sample well avoiding air bubbles.

\subsubsection{Results}

Results were read in 15 minutes. Positive results were visible within one minute. Negative Result: If only the $\mathrm{C}$ band is developed on the HBsAg, HBsAb, HBeAg strip or both $\mathrm{C}$ and $\mathrm{T}$ bands are developed on either the $\mathrm{HBeAb}$ or the $\mathrm{HBcAb}$ strip, the test indicates the absent of the parameter being tested. Positive Result: If both $\mathrm{C}$ and $\mathrm{T}$ bands are developed on the $\mathrm{HBsAg}$, or $\mathrm{HBsAb}$, or $\mathrm{HBeAg}$ strip or only the $\mathrm{C}$ band is developed on the $\mathrm{HBe} A b$ or $\mathrm{HBcAb}$ strip, the test indicates the presence of the parameter being tested. Invalid: If no $\mathrm{C}$ band is developed, the assay on the strip is invalid regardless of color development on the $\mathrm{T}$ band.

\subsection{Statistical Analysis}

The data obtained was analyzed using statistical package for social sciences (SPSS) version 22.Chi- square test was used $(\mathrm{P} \leq 0.05)$.

\section{Result}

Of the 196 samples screened, 11(5.6\%) tested positive for HBsAg. Male subjects recorded a prevalence of 8/93 (8.6\%) while female subjects had a prevalence of $3 / 103(2.9) . \mathrm{X}^{2}=$ 2.987; $\mathrm{P}=0.042 ; \mathrm{P}<0.05$ (Table 1).

Table 2: Indicates the age distribution of HBV infection 
where ages $16-30$ years had the highest prevalence of 7/79 $(8.9 \%)$, followed by ages $31-45$ years with prevalence of $1 / 22(4.5 \%)$ and ages $0-15$ years had the least prevalence of $3 / 86(3.5 \%) . \mathrm{X}^{2}=2.889 ; \mathrm{P}=0.577 ; \mathrm{P}>0.05$.

Table 3: showed distribution of HBsAg among participants in relation to risk factors. Individual with multiple sex partners had prevalence of $1 / 56(1.8 \%)$ while those without multiple sex partners revealed prevalence of 10/140 (7.1\%). $\mathrm{X}^{2}=2.167 ; \mathrm{P}=0.141 ; \mathrm{P}>0.05$. Prevalence of HBsAg in relation to history of blood transfusion shows that, people with history of blood transfusion (17) had prevalence of
$1(5.9 \%)$, while those without the history of blood transfusion (179) had prevalence of $10(5.6 \%) . X^{2}=0.003 ; P=0.960$; $\mathrm{P}>0.05$. Regarding surgical history $0 / 18(0.0 \%)$ no case of hepatitis $\mathrm{B}$ infection was recorded, while a prevalence of $11 / 178(6.2 \%)$ was noted among individuals without a history of surgery. $\mathrm{X}^{2}=1.178 ; \mathrm{P}=0.278 ; \mathrm{P}>0.05$.

The distribution of HBsAg with respect to sharing of sharp objects showed a higher prevalence of $8(6.3 \%)$ in those that share sharp objects, while $3(4.3 \%)$ prevalence was recorded in those who do not share sharp objects. $\mathrm{X}^{2}=0.362 ; \mathrm{P}=$ $0.548 ; \mathrm{P}>0.05$.

Table 1. Distribution of HBsAg among Jessu Community in Relation to Sex.

\begin{tabular}{llll}
\hline HBsAg Rapid Test HBV 5 Parameter Test & & \\
\hline Sex & No. Tested & No. Pos. (\%) & No. Confirmed Pos. (\%) \\
\hline Male & 93 & $8(8.6)$ & $8(8.6)$ \\
Female & 103 & $3(2.9)$ & $3(2.9)$ \\
TOTAL & 196 & $11(5.6)$ & $11(5.6)$ \\
\hline
\end{tabular}

$\mathrm{X}^{2}=2.987 ; \mathrm{P}=0.04$

Table 2. Distribution of HBsAg among Jessu Community in Relation to Age.

\begin{tabular}{llll}
\hline HBsAg Rapid Test HBV 5 Parameter Test & & \\
\hline Age Group & No. Tested & No. Pos. (\%) & No. Confirmed Pos. (\%) \\
\hline $0-15$ & 86 & $3(3.5)$ & $3(3.5)$ \\
$16-30$ & 79 & $7(8.9)$ & $7(8.9)$ \\
$31-45$ & 22 & $1(4.5)$ & $1(4.5)$ \\
$46-55$ & 6 & $0(0.0)$ & $0(0.0)$ \\
$56-a b o v e$ & 3 & $0(0.0)$ & $0(0.0)$ \\
TOTAL & 196 & $11(5.6)$ & $11(5.6)$ \\
\hline
\end{tabular}

$\mathrm{X}^{2}=2.889 ; \mathrm{P}=0.577$

Table 3. Prevalence of HBsAg among Jessu Community in Relation to HBV risk factors.

\begin{tabular}{|c|c|c|c|c|}
\hline \multicolumn{5}{|c|}{ Risk HBsAg Rapid Test HBV 5 Parameter Test } \\
\hline Factors & Tested & No. Pos. (\%) & Confirmed Pos. (\%) & $\mathrm{X}^{2} / \mathrm{P}$ Value \\
\hline \multicolumn{5}{|c|}{ Multiple sex partners } \\
\hline Yes & 56 & $1(1.8)$ & $1(1.8)$ & $X^{2}=2.167$ \\
\hline No & 140 & $10(7.1)$ & $10(7.1)$ & $\mathrm{P}=0.141$ \\
\hline Total & 196 & $11(5.6)$ & $11(5.6)$ & \\
\hline \multicolumn{5}{|c|}{ Blood Transfusion } \\
\hline Yes & 17 & $1(5.9)$ & $1(5.9)$ & $X^{2}=0.003$ \\
\hline No & 179 & $10(5.6)$ & $10(5.6)$ & $\mathrm{P}=0.960$ \\
\hline Total & 196 & $11(5.6)$ & $11(5.6)$ & \\
\hline \multicolumn{5}{|l|}{ Surgery } \\
\hline Yes & 18 & $0(0.00)$ & $0(0.00)$ & $X^{2}=1.178$ \\
\hline No & 178 & $11(6.2)$ & $11(6.2)$ & $\mathrm{P}=0.278$ \\
\hline Total & 196 & $11(5.6)$ & $11(5.6)$ & \\
\hline \multicolumn{5}{|c|}{ Sharing of sharps } \\
\hline Yes & 126 & $(6.3)$ & $8(6.3)$ & $X^{2}=0.362$ \\
\hline No & 70 & $3(4.3)$ & $3(4.3)$ & $\mathrm{P}=0.548$ \\
\hline Total & 196 & $11(5.6)$ & $11(5.6)$ & \\
\hline
\end{tabular}

\section{Discussion}

This study revealed $5.6 \%$ seroprevalence of HBV infection (HBsAg) among residence of Jessu Community Gombe State, Nigeria, placing Gombe State, specifically Jessu community as an area of intermediate HBV endemicity (2$7 \%$ of HBsAg positive) according to World Health Organization criteria [9]. The result of this study was in conformity with $5.3 \%$ prevalence reported by Ndako [15] in
Billiri Local Government of Gombe State, Nigeria, and 6\% prevalence reported by Adoga [4] among blood donors in Nasarawa State. The result is, however, lower when compared to $12.8 \%$ prevalence reported by Obi [16] among HIV patients in Borno and Gombe States of Nigeria, $8 \%$ prevalence reported by Isa [17] among Children attending Mohammed Shuwa Memorial Hospital Maiduguri, Borno State.

The result also showed a sharp declined of HBsAg prevalence when compared to $14 \%$ prevalence reported by 
Wasa and Maigana [18] among undergraduate students of Gombe State University, 26.5\% prevalence reported by Mustapha and Jibrin [19] among HIV patients in Gombe, Gombe State.

Gender distribution, revealed higher HBsAg prevalence in males $(8.6 \%)$ compared to females $(2.9 \%)$ counterpart, despite the high number of females (103) participation, the difference was significant $(\mathrm{p}=0.04)$. This is similar to what was reported by Okonko [20] with HBsAg prevalence higher among males (10.2\%) than the females (5.9\%), Wasa and Maigana[18] found higher HBsAg prevalence among males (20\%) than females $(5 \%)$, Mehmet [21] reported higher prevalence rate of $12.7 \%$ in males than $2.1 \%$ in females. The reasons for the high rate of prevalence among the males may be due to habits such as use of sharp objects in tattooing, intravenous drugs usage, homosexualism and keeping multiple sexual partners (sometimes encouraged on religion/cultural ground) which may be common among the males than in females counterparts and may play a role in the higher prevalence observed among men compared to women. The higher prevalence observed in males $(8.6 \%)$ by this study contradicts findings of Okonko [20] who reported a higher HBsAg prevalence in females (10.2\%) than males (5.5\%), Sule [22] reported higher HBsAg seropositivity among females $(15.6 \%)$ than the males $(11.7 \%)$, Okechukwu [23] found higher prevalence in females $(65.5 \%)$ than males $(34.4 \%)$. The disparity may be attributed to the differences in socio-cultural, religious beliefs and the sample size or methodology used in the study areas and populations considered.

Age distribution of HBsAg showed age group 16-30 years had the highest prevalence of $8.9 \%$, followed by ages $31-45$ years with $4.5 \%$ prevalence and ages $0-15$ years with $3.5 \%$ prevalence. Statistically, the difference observed among age group in this study was not significant $(p=0.577)$. This is similar to the report of Okonko [20] that age was not significantly associated with HBsAg seropositivity among attendees of Association for Reproductive Family and Health (AFRH) Centre in Ibadan, Nigeria. Age of acquiring infection is the major determinant of the incidence and prevalence rates [11]. Higher HBsAg prevalence has been previously reported among younger age groups in some parts of Nigeria and outside Nigeria. Okonkwo [20] reported the highest prevalence among ages 16-29 years; Khan [5] found the highest prevalence among ages 21-30 years. Okechukwu [23] found the highest prevalence of HBsAg among ages 2130 years. Mustapha and Jibrin [19] reported the highest prevalence among ages 40-49yeas, Adewole [24] reported the highest prevalence among ages $30-40$ years, Sule [22] reported the highest prevalence among ages $40-80$ years. The findings may be due to the fact that most of the participants fall within the age range of high sexual activity thus supporting the role of sex in the viral transmission. In addition, youthful exuberance, sharing of contaminated sharp objects for fashionable expressions such as tattoo, ear and nose piercing increases their risk of exposure to infection.

The distribution of HBsAg in relation to the history of blood transfusion showed that those with a prior history of transfusion recorded the higher prevalence of $5.9 \%$ than those with no history of blood transfusion. High risk of HBV infection in most of the developing and underdeveloped world countries is due to lack of proper screening of blood. All blood donations should be screened for evidence of infection including HBV prior to the release of blood and blood components for clinical use. This study revealed that $6.2 \%$ prevalence had no prior history of surgery while $0.0 \%$ prevalence had a prior history of surgery suggesting that surgery is not related to HBV infection in Gombe State, Nigeria. Participants who share sharp objects recorded a higher prevalence of $6.3 \%$ when compared to $4.3 \%$ prevalence of those who do not share sharp objects. This is similar to the report of Edia-Asuke [25].

\section{Conclusion}

The prevalence of $5.6 \% \mathrm{HBsAg}$ among residence of Jessu Community Gombe State, Nigeria, revealed that HBV is endemic in Gombe State and Nigeria and there is a sharp declined of HBsAg prevalence when compared to $14 \%$ prevalence reported by Wasa and Maigana, [18] among undergraduate students of Gombe state University, Gombe state. This decline may be due to interventions by non governmental organizations on HIV/AIDS as prevention measures for HIV/AIDS can also prevent HBV infection. This study has provided additional information on the burden of HBV infection to the existing stock in Gombe State and Nigeria.

\section{References}

[1] TerwaseJM, and Chima K. Emeka.Prevalence of Hepatitis B Surface Antigen among Residents of Julius Berger Staff Quarters, Kubwa,Abuja. International Journal of Prevention and Treatment.2015; 4(2): 29-33.

[2] Sarin S. K, M. Kumar, G. K. Lau, Z. Abbas, H. L. Y. Chan, C. J. Chen, D. S. Chen, H. L. Chen, P. J. Chen, R. N. Chien, A. K. Dokmeci, Ed Gane, J. L. Hou, W. Jafri, J. Jia, J. H. Kim, C. L. Lai, H. C. Lee, S. G. Lim, C. J. Liu, S. Locarnini, M. Al Mahtab, R. Mohamed, M. Omata,J. Park, T. Piratvisuth, B. C. Sharma, J. Sollano, F. S. Wang, L. Wei, M. F. Yuen, S. S. Zheng, and J. H. Kao. Asian-Pacific clinical practice guidelines on the management of hepatitis B: update, Hepatology International. 2016; 10:1-98.

[3] Okoye, Ikem Chris and Samba, ScholasticaAtteh.SeroEpidemic Survey of Hepatitis B in a Population of Northern Nigeria.Animal Research International.2006;3(2): 485 - 488.

[4] Adoga Moses P, Silas D. Gyar, Simon Pechulano, Obadiah D. Bashayi, Samuel E. Emiasegen, Timothy Zungwe, Odunayo H. Iperepolu, ChinweAgupugo, Simon M. Agwale. Hepatitis $B$ virus infections in apparently healthy urban Nigerians: data from pre-vaccination tests, Journal of Infect Developing Countries. 2010;4(6):397-400.

[5] Khan F., Shams S., Ihteshamud Din Qureshi ID., Israr M., Khan H.,Sarwar MT and Muhammad Ilya M. Hepatitis B virus infection among different sex and age groups in Pakistani. Virology Journal.2011; 8:225. 
[6] Geberemicheal A,Gelaw A, Moges F, D. M.Seroprevalence of hepatitis B virus infections among health care workers at the BulleHoraWoreda Governmental Health Institutions, Southern Oromia, Ethiopia. Journal Environ Occup Sciences. 2013; 2(1), 9-14.

[7] Kennedy Okyere. Prevalence of Hepatitis B and C viral infections among children and adults presenting with hepatic disease at komfoanokye teaching hospital. http:/hdl.handle.net/123456789/10109 2016; 1-21.

[8] Geoffrey Zambezi Mutuma, Margaret W. Mbuchi, EberhardZeyhle, RanaFasana, Fredrick A. Okoth J. MainaKabanga, Kuria Julius, T., LusesoShiramba, M. KariukiNjenga, Peter. M. Kaiguri, Vincent Osidiana. Prevalence of Hepatitis B Virus (HBV) surface antigen and HBVassociated hepatocellular carcinoma in Kenyans of various ages, African Journal of Health Sciences. 2011;18 (1-2). 53-61.

[9] WHO. Fact sheet on Hepatitis B, World Hepatitis day, July 28. 2015; 1.

[10] Norah A. Terrault, Natalie H. Bzowej, Kyong-Mi Chang, Jessica P. Hwang, Maureen M. Jonas, and M. Hassan Murad.AASLD Practical Guidelines for Treatment of Chronic Hepatitis B. Official Journal of the American for the study of liver disease. 2011; 63 (1) $262-263$.

[11] WHO. Increase awareness and understanding of viral hepatitis. World hepatitis day, 28, July 2017; 1

[12] Himont Bhattacharya, Debdutta Bhattacharya, S.R. Ghosal, Subarna Roy, \& Sugunan A.P. Status of hepatitis B infection a decade after hepatitis B vaccination of susceptible Nicobarese, an indigenous tribe of Andaman \& Nicobar $(A \& N)$ islands with high hepatitis B endemicity, Indian Journal of Medicine Res. 2015; 141: 653-661.

[13] Fuqiang Cui, LipinShen, Li LiHuaqing Wang, Fuzhen Wang, Shengli Bi, Jianhua Liu, Guomin Zhang, Feng Wang, HuiZheng, Xiaojin Sun, Ning Miao, Zundong Yin, ZijianFeng, Xiaofeng Liang, Yu Wang.Prevention of Chronic Hepatitis B after three Decades of Escalating Vaccination Policy, China; Emerging Infectious Diseases.2017; 23 (5). 765 - 767.

[14] Thrusfield, M.V. Veterinary epidemiology. 3rd edn, UK, Blackwell Science. 2005; 178-179.

[15] Ndako JA., Yahaya A., JosephineAmira JO., Debby T.Olaolu DT., Akande TA.Hepatitis B Virus (HBV) Infection among Alcoholic Consumers at a Local Community, North-East Nigeria.Journal of Natural Sciences Research.2013; 3(13): 2224-3186.
[16] Obi, O.S; Baba, H.A; Baba, M.M; Amilo, G.I; Bukar, A. The effect of co-infection of HIV and Hepatotropic viruses on selected Biochemical and Haematological markers of patients in North-Eastern Nigeria. Intl journal of tropical diseases and health. 2014 ; 4(5): 568-581.

[17] Isa MA.,Bello HS.,Gulani IA., Aliyu B. and Iliya H. Prevalence of Hepatitis B virus infection among children attending mohammedshuwa memorial hospital Maiduguri, Borno state, Nigeria; International Journal of Advanced Research in Biological Sciences. 2015; 2348-8069.

[18] Wasa A. A and Maigana A. Prevalence of Hepatitis B Surface Antigen among Undergraduate Students of Gombe State University, Gombe.IOSR Journal of Pharmacy and Biological Science. 2013; 6 (6): 24-27.

[19] Mustapha, S.K and Jibrin.The prevalenceof Hepatitis B surfaceantigemia in patients with HIV infection in Gombe, Nigeria.African Medical Journal. 2004; 4:10-11.

[20] Okonko. IO.,Okerentugba PO. andAkinpelu AO. Prevalence of HBsAG among Attendees of ARFH Centre in Ibadan, Southwestern Nigeria; American-Eurasian Journal of Scientific Research. 2012; 7 (3): 100-105.

[21] Mehment D., Melksah E., Sherif Y., GunayS., Tuner O., ZeryepS.Prevalence of Hepatitis B Infection in the Southeastern Region of Turkey, Comparison of Risk Factors for HBV Infection in Rural and Urban Areas.Journal Infectious Diseases.2005; 58:15-19.

[22] Sule WF., I.O. Okonko IO., I.P. Yunusa IP., OduNN., N. Frank-Peterside N. Detection of Hepatitis B surface antigen and risk factors of transmission among HIV patients attending Universal Hospital Ankpa, Kogi State, Nigeria.Nature and Science. 2010; 9(10): 37-44.

[23] Okechuckwu N., Godwin M., Egeudenia O., E. Desmond E., Patrick O. The Seroprevalence of Hepatitis B Viral Infection in HIV Tested Positive Individuals in Owerri, Imo State, Nigeria. Journal.Aids Clinical. Rec.2014; 5:273.

[24] Adewole R. A, Omilabu S. A, Ayodele A. O. S, Gbotolorun O. $\mathrm{M}$, and Anorue E.I. Prevalence of hepatitis B virus surface antigen (HBsAg) in patients attending dental centre of a tertiary hospital (a pilot study). Journal of Medicine and Medical Sciences 2013; 4(7): 275-279.

[25] Edia-Asuke A.U., Abubakar Z., and Asuke S.Seroprevalence of Hepatitis B Infection among out-patieents Attending a Public Tertiary Institution in Kaduna State, Nigeria. Journal of Tropical Medicine and Surgery 2015; 3 (3):189-192. 